\title{
Human tissue samples more difficult to obtain for academics
}

Britain is to establish a national database correlating genetic information with medical histories and lifestyle data on 500,000 volunteers. The $£ 45$ million (\$65 million) BioBank project is intended to provide a resource that will help researchers unravel the origins of a variety of illnesses.

However, its launch coincides with reports that researchers face increasing difficulties in obtaining samples of diseased human tissue-material that will be vital for studies complementary to the BioBank data to determine which genes and proteins are abnormal in a given disease state.

The drop in available samples was thought to be due to public outcry over events such as that at Alder Hey hospital near Bristol, where surgical staff had been removing organs from children who had died and preserving them for future research, without consulting the children's parents. But the fall-off in donations was relatively small and only temporary. It seems instead that the problem lies with the medical intermediaries, ranging from pathologists to ethical review boards, involved in the collection and distribution of such material.

"At present, the proportion of those we ask who give their consent to tissue removed during surgery being used for research is more than 99\%," says Neil Grey of the Peterborough Hospital Human Research Tissue Bank, one of Britain's leading suppliers of human tissue for research purposes.

A spokesperson for Pharmagene, a private company engaged in securing human tissue samples for drug research, agrees: "In fact, the events at Alder Hey and elsewhere have yielded a positive outcome in that there has been an increase in public awareness of the potential for the use of human tissue for research purposes. Whilst we did experience a temporary reduction in the frequency with which tissue was made available, this resulted not from patients refusing to give consent for the tissues to be used for research, but from those people involved in the supply...of tissues."

Removal of a piece of tissue during surgery requires that informed consent be obtained from the patient, that an independent research ethics committee approve the supply of tissue to researchers and companies, and that patient confidentiality be maintained. Although this system may be working for private companies, academic researchers are having difficulties with the flow of material.

Scientists are finding the new regulations and monitoring practices introduced in the wake of public concern over the events at Alder Hey to be cumbersome and restrictive to work with. "There has recently been a tremendous seachange in the availability of human tissue for research," says Anne Bishop, a senior lecturer who specializes in lung tissue repair and regeneration at the Tissue Engineering Centre at the Imperial College of Science, Technology and Medicine in London. "The new regulations and practices have tied the hands of people who need to be much freer."

Bishop quotes the example of a team of researchers who failed to obtain a particular sample they had been promised because the administrator responsible for overseeing the deal could not be found at the moment that the tissue was extracted from the patient during surgery.

David Dickson, London

\section{Local IRBs fail to assess remote human studies}

Most of our readers may not have heard of Staffordshire University, but biomedical researchers at this tiny British institution have succumbed to the same problem that these days seems to plague their much larger and more prestigious counterparts. Last month it came to light that a research project involving human subjects has not been properly approved by the university's internal ethical review board. An investigation is underway.

Meanwhile, the report of an investigation into the conduct of scientists from the Harvard School of Public Health (HSPH) has just been released. Professor of medicine David Christiani and his associate Xiping $\mathrm{Xu}$ carried out 12 studies in rural China, but failed to inform subjects about risks they took by participating in the research, a federal investigation concluded last week.

The studies began in the mid-1990s, and most sought to evaluate genetic and environmental causes of ailments ranging from obesity to respiratory diseases. For example, one study assessed the genetic susceptibility to the effects of aromatic solvents on reproductive health; another ex- amined the relationship between rotating shift work and reproductive outcomes.

Although the investigation by the Office for Human Research Protection (OHRP) found no evidence that subjects were physically harmed as a result of defects in the studies, the OHRP cited numerous failings by the researchers to disclose key information about their investigations to participants, and also found fault with the Institutional Review Board (IRB) at HSPH. Consent forms did not thoroughly explain the research and were written in language that was too complex for the participants to understand. Furthermore, although the IRB questioned certain practices, it approved them anyway, and it did not thoroughly review the ongoing projects once they were approved.

Protocols for research in developing countries may need to take into consideration more complicated questions than do domestic research protocols. There are a number of guidelines for dealing with these issues, which may related to differences in social, economic, cultural and environmental milieus as compared to those in developed nations. New guidelines, entitled The Ethics of Research Related to Healthcare in Developing Countries, were released this April by the UK-based Nuffield Council on Bioethics. Among the topics addressed in this document are the need for development of local expertise and ethical review in the host country, and the requirement that successful treatments be made available after a clinical trial is completed.

The Nuffield guidelines follow similar suggestions made by the now-defunct US National Bioethics Advisory Commission in April 2001. Both sets of guidelines stress the need for ethical capacity building in the countries where research takes place. "Do IRBs [back home] have enough knowledge about the issues raised by research conducted in developing countries?" questions attorney and bioethicist Rebecca Dresser of Washington University in St. Louis, a member of the President's Council on Bioethics. "I don't think you can expect IRBs here to do a complete job, as they don't have the local knowledge."

Myrna E. Watanabe, Patterson 